\title{
A relict stem salamander: Evidence from the Early Cretaceous of Siberia
}

Pavel P. Skutschas

Acta Palaeontologica Polonica 61 (1), 2016: 119-123 doi:http://dx.doi.org/10.4202/app.00124.2014

The early evolution of salamanders, which are one of the three living groups of lissamphibians, is not well known. Both stem- and crown-group salamanders first appeared in the Middle Jurassic (Bathonian), but subsequently had different evolutionary histories: stem salamanders were thought to have gone extinct in the Late Jurassic, while crown salamanders persist to the present day. Here, I report the discovery of an indeterminate stem salamander in the Lower Cretaceous (Aptian-Albian) Ilek Formation of Western Siberia. This is new evidence that the most basal salamanders survived beyond the Jurassic-Cretaceous boundary and co-existed with crown-group salamanders during approximately the first 40 million years of the known history of salamanders. The recognition of stem salamanders in the Early Cretaceous of Western Siberia adds to the inventory of taxa that suggest this area was a refugium for various groups of vertebrates with Jurassic affinities.

Pavel P. Skutschas [skutchas@mail.ru], Saint Petersburg State University, Vertebrate Zoology Department, Faculty of Biology, Universitetskaya nab. 7/9, Saint Petersburg 199034, Russian Federation; Laboratory of Mesozoic and Cenozoic Continental Ecosystems, Tomsk State University, Prospekt Lenina 36, 634050, Tomsk, Russia.

This is an open-access article distributed under the terms of the Creative Commons Attribution License (for details please see creativecommons.org), which permits unrestricted use, distribution, and reproduction in any medium, provided the original author and source are credited. 